\title{
Therapeutic effects of liver soothing pingchuan formula decoction on experimental asthma in BALB/c mice via regulation of nerve growth factor-tyrosine kinase A pathway
}

\author{
XIN-GUANG ZHANG ${ }^{1,2^{*}}$, ZHENG XUE ${ }^{1,2 *}$, YI-TAO ZHAO $^{2,3}$, LI BAI $^{1,2}$, FEI LIU $^{1,2}$, \\ LI-QING LI ${ }^{1,2}$, JIE WU ${ }^{1,2}$, JING-DONG ZHOU ${ }^{1,2}$ and JIAN-ER YU ${ }^{1,2}$ \\ ${ }^{1}$ Department of Pediatrics, Shanghai Municipal Hospital of Traditional Chinese Medicine; \\ ${ }^{2}$ Pediatric Institute of Shanghai Traditional Chinese Medicine Academy, Shanghai 200071; ${ }^{3}$ Department of Pediatrics, \\ Guangdong Provincial Hospital of Traditional Chinese Medicine, Guangzhou, Guangdong 510120, P.R. China
}

Received August 16, 2016; Accepted June 27, 2017

DOI: $10.3892 / \mathrm{mmr} .2018 .8747$

\begin{abstract}
The present study was designed to investigate the effects of liver soothing pingchuan formula decoction (LSPF) on experimental asthma in BALB/c mice and explore its potential molecular mechanisms. An animal model of asthma was established in BALB/c mice through sensitization and activation with intraperitoneal injection of $10 \%$ ovalbumin $(\mathrm{OVA}) / \mathrm{Al}(\mathrm{OH})_{3}$ solution in addition to inhalation of a $5 \%$ OVA solution. LSPF (300 and $600 \mathrm{mg} / \mathrm{kg} /$ day) was initially administered orally prior to activation. Following this, bronchoalveolar lavage fluid (BALF) and lung tissues were collected for histopathalogical examination. Levels of inflammatory cells and cytokines were determined in the BALF, and levels of nerve growth factor (NGF) and tyrosine kinase A (TrkA) in the lung tissues were determined. The results of the present study indicated that increased inflammatory reactions were observed following OVA sensitization $(\mathrm{P}<0.05)$, and the expression levels of NGF $(\mathrm{P}<0.05)$ and TrkA $(\mathrm{P}<0.05)$ were significantly increased, compared with normal mice. Notably, compared with the asthma model group,immunohistochemical results revealed that LSPF treatment suppressed OVA induced inflammatory reactions $(\mathrm{P}<0.05)$ and NGF $(\mathrm{P}<0.05)$ and TrkA expression levels $(\mathrm{P}<0.05)$. In addition, the NGF $(\mathrm{P}<0.05)$ and TrkA $(\mathrm{P}<0.05)$ were revealed to be downregulated with LSPF treatment from the results of the ELISA and western blotting assay. Overall, the results of the present study demonstrated
\end{abstract}

Correspondence to: Dr Jian-Er Yu, Department of Pediatrics, Shanghai Municipal Hospital of Traditional Chinese Medicine, 274 Zhijiang Road, Shanghai 200071, P.R. China

E-mail: jianeryuphd@163.com

*Contributed equally

Key words: Asthma, liver soothing pingchuan formula decoction, nerve growth factor, tyrosine kinase A, nerve growth factor-tyrosine kinase A pathway that LSPF exhibits therapeutic effects on experimental asthma in mice, via downregulation of the NGF-TrkA pathway.

\section{Introduction}

Asthma is a chronic disease characterized by serious airway edema \& inflammation, excessive phlegm, wheezing, chest tightness and shortness of breath and remains one of the most common chronic diseases in children worldwide $(1,2)$. The available conventional medical therapies only temporarily relieve or control the asthma symptoms and a radical cure for asthma has not yet emerged from ongoing research $(3,4)$. In addition, it has previously been reported that currently $5-10 \%$ of pediatric asthma patients exhibit persistent asthma symptoms (5). Furthermore, the currently used drugs for treating asthma commonly result in various intolerable side-effects (2-4). Therefore, the investigation for novel, safe and reliable therapeutic strategies for treating pediatric asthma is of primary concern.

Nerve growth factor (NGF) exerts an important functional effect on the pathogenesis of allergic diseases through regulating neuronal plasticity and connecting neuro-immune mechanisms in immune cells and neurons (6,7). Increasing evidence suggests that NGF mediates airway hyperresponsiveness and induces airway inflammation by causing neurogenic inflammation and amplifying immune cell effects $(8,9)$. The diverse actions of NGF are mediated by its binding to a specific high affinity NGF receptor (TrkA) (10,11). Inhibition of NGF/TrkA signaling ameliorates airway remodeling in chronic allergic airway inflammation (12). Kinase D-interacting substrate of $220 \mathrm{kDa}$ and SH2B adapter protein 1 participate in part to the pathogenesis of asthma through the NGF-TrkA signaling pathway $(13,14)$.

It is well known that herbal medicines have been used to treat various diseases with low toxicity, and they are important resources for discovering effective candidate drugs to treat asthma $(15,16)$. Liver soothing pingchuan formula decoction (LSPF) is an effective and empirical herbal medicinal prescription for treating asthma and is composed of 12 herbal medicines which are listed in Table I. It can upregulate the 
ratio of interferon- $\gamma /$ interleukin (IL)-4 and resolve phlegm and stasis to alleviate asthma $(17,18)$. However, research using animal models of asthma to provide experimental proof and investigate the effectiveness of LSPF and its associated pharmacological mechanism, is limited and is therefore of primary concern. The present study aimed to investigate the therapeutic effects of LSPF on experimental asthma in BALB/c mice and explore the potential underlying molecular mechanisms, which would aid in expanding the knowledge and use of LSPF in hospitals to treat asthma.

\section{Materials and methods}

Reagents and equipment. Ovalbumin (OVA) was purchased from Shanghai Junhao Chemical Co., Ltd. (Shanghai, China). Murine antibodies of NGF (diluted at 1:50) and TrkA (diluted at 1:100) were purchased from Abcam (Cambridge, UK). Enzyme-linked immunosorbent assay (ELISA) kits including TrkA, NGF, immunoglobulin (Ig) E, IL-13 and IL-18 were obtained from RayBiotech Inc. (Norcross, GA, USA). EnVision reagent was obtained from Dako; Agilent Technologies, Inc. (Santa Clara, CA, USA) and horseradish peroxidase (HRP) conjugated anti-mouse antibodies were obtained from Beyotime Institute of Biotechnology (Shanghai, China). Optical densities of samples were determined using an MK3 microplate reader (Labsystems Diagnostics, Vantaa, Finland). A Mini-PROTEAN 3 Cell (Bio-Rad Laboratories, Inc., Hercules, CA, USA) was used for electrophoresis. Dexamethasone (Dxm) acetate tablets $(0.75 \mathrm{mg} / \mathrm{tablet})$ were provided by the Shanghai Xinyi Pharm. Co., (Shanghai, China).

Preparation of LSPF. The preparation of LSPF was performed as previously described (19). In brief, the 12 herbal medicines were powdered and decocted with 6 times water (v/w) for 2-3 h. Following purification by precipitation using $95 \%$ ethanol, the filtrates were concentrated by using rotary evaporators at a temperature of $60^{\circ} \mathrm{C}$. Finally, the fluid extracts of LSPF were obtained, and the yields of the LSPF extracts were calculated as approximately $8 \%$ [yield $(\%)=$ weight of extracts/total weight of herbal medicines x100].

High-performance liquid chromatography (HPLC) assay for LSPF. An Agilent 1100 HPLC system [(Agilent Technologies, Inc.; equipped with a quaternary pump, an auto-sampler, a degasser, an automatic thermostatic column compartment, a DAD and a liquid chromatography/mass spectrometry (MS) D Trap XCT electrospray ionization tandem (ESI) mass spectrometer] was used for the separation. The separation was performed on a GS-120-5- $\mathrm{C}_{18}$-BIO chromatographic column (5 $\mu \mathrm{m}, 250 \times 4.6$ mm, i.d.; Qbiogene, Inc., Carlsbad, CA, USA) with the column temperature set at $35^{\circ} \mathrm{C}$. A linear gradient elution of $\mathrm{A}$ ( $0.1 \%$ formic acid water) and B (acetonitrile) was used with the gradient procedure as follows: $0 \mathrm{~min}, \mathrm{~B} 5 \%$, to $60 \mathrm{~min} B 40 \%(\mathrm{v} / \mathrm{v})$. The flow rate was $1.0 \mathrm{ml} / \mathrm{min}$ and the injection volume was $10 \mu \mathrm{l}$. DAD was on and the target wavelength was simultaneously set at $210 \mathrm{~nm}$. The split ratio to the mass spectrometer was 1:3. The acquisition parameters for negative ion mode were: collision gas, ultra high-purity helium (He), nebulizer gas (N2), 35 psi, drying gas (N2), 10 1/min, drying temperature, $350^{\circ} \mathrm{C}, \mathrm{HV}, 3500 \mathrm{~V}$, mass scan range, $\mathrm{m} / \mathrm{z}$
Table I. Compositions of liver soothing pingchuan formula.

\begin{tabular}{llc}
\hline & \multicolumn{1}{c}{ Herbal medicine name } & Weight $(\mathrm{g})$ \\
\hline 1 & Bupleuri Radix & 10 \\
2 & Scutellariae Radix & 10 \\
3 & Glycyrrhizae Radix Et Rhizoma & 10 \\
4 & Armeniacae Semen Amarum & 10 \\
5 & Raphani Semen & 10 \\
6 & Pheretima & 10 \\
7 & Persicae Semen & 10 \\
8 & Zanthoxyli Pericarpium & 10 \\
9 & Perillae Fructus & 10 \\
10 & Paeoniae Radix Alba & 10 \\
11 & Ephedrae Herba & 5 \\
12 & Salviae Miltiorrhizae Radix Et Rhizoma & 5 \\
Total & & 210 \\
\hline
\end{tabular}

100-2,200, target mass, $500 \mathrm{~m} / \mathrm{z}$, compound stability, $100 \%$, trap drive level, $100 \%$. All the data were analyzed using Chemstation software (version 10.01; Agilent Technologies, Inc., Santa Clara, CA, USA).

Animals and asthma model establishment. A total of 50 specific pathogen-free male BALB/c mice (body weight, 16-20 g; age, 3-5 weeks) were purchased from the Shanghai Laboratory Animal Research Center (Shanghai, China), license number, SCXK 2008-0016. Mice were housed separately in the animal facility at a temperature of $25^{\circ} \mathrm{C}$ with a $12 \mathrm{~h} \mathrm{light/dark}$ cycle and humidity of 60-70\% with free access to food and water.

The mice were randomly divided into 5 groups $(n=10)$ : i) Normal control; ii) asthma model control; iii) asthma mice treated with positive drugs (Dxm); iv) asthma mice treated with $300 \mathrm{mg} / \mathrm{kg} /$ day LSPF; and v) asthma mice treated with $600 \mathrm{mg} / \mathrm{kg} /$ day LSPF. Mice in groups ii)-v) were sensitized on days 1 and 15 by intraperitoneal injection of $10 \%$ OVA/Al $(\mathrm{OH})_{3}$ solution $(1 \mathrm{ml})$. On days 23-29, mice were challenged for 40 min each day with an aerosolized solution of 5\% OVA in distilled water in a 5-1 closed chamber. In addition, mice in control group were subjected to the same treatment with an equal amount of saline instead of OVA/Al $(\mathrm{OH})_{3}$ solution. The asthma model was further validated as follows: Asthmatic mice exhibited a $20 \%$ increase in respiration rate and a $10 \%$ decrease in body weight, compared with the normal controls. The asthmatic mice displayed additional symptoms, including irritability, muscle twitching, stool incontinence, unkempt fur, reduced activity, reduced food intake, and nasal/oral cyanosis. The IgE levels in bronchoalveolar lavage fluids (BALFs) and eosinophil numbers were increased in asthma mice. Furthermore, lung histology in these mice was consistent with the symptoms of asthma. The present study was approved by the Ethics Committee of Shanghai Municipal Hospital of Traditional Chinese Medicine (Shanghai, China).

Drug administration and sample collection. The administered drug doses were calculated and scaled down according to the clinical uses in children $(20,21)$. During days 30-43, 
in addition to the routine diet, mice were treated orally with Dxm (1.5 mg/kg/day) and LSPF (300 and $600 \mathrm{mg} / \mathrm{kg}$ ), and the normal and asthma model mice were treated orally with equal volumes of saline. On day 44, following obtainment of BALFs and tissue samples from the right lung, all the samples were stored at $-80^{\circ} \mathrm{C}$ until further use.

Inflammatory cell count and cytokine determination in $B A L F s$. Total inflammatory cell numbers, including white cells and eosinophil cells were assessed by counting cells with a hemocytometer. Cytokines and enzymes including TrkA (cat. no. DG30689M; Beijing Dongge Biotechnology Co., Ltd., Beijing, China), NGF (cat. no. YM-QX2878; Shanghai YuanMu Biological Technology Co., Ltd., Shanghai, China), IgE (cat. no. RAB0799; Sigma-Aldrich; Merck KGaA, Darmstadt, Germany), IL-13 (cat. no. RAB0257; Sigma-Aldrich; Merck KGaA) and IL-18 (cat. no. BMS618-3; Thermo Fisher Scientific, Inc., Waltham, MA, USA) were determined by using the commercial ELISA kits according to the manufacturer's protocol.

Lung tissue histopathological examination. Lung tissue was fixed in $10 \%$ formalin for $48 \mathrm{~h}$ at room temperature and then tissues sections $(4-7 \mu \mathrm{m})$ were prepared as previously described (22). Subsequently, the tissue sections were stained using the Ventana Benchmark automated staining system (Ventana Medical Systems, Inc., Tucson, AZ, USA) with primary antibodies for NGF (cat. no. ab6199; Abcam) and TrkA (cat. no. ab76291; Abcam) for $1 \mathrm{~h}$ at room temperature, followed by incubation with EnVision ${ }^{+} / \mathrm{HRP} / 3$ secondary antibody (cat. no. K400011; Dako; Agilent Technologies, Inc.) for $30 \mathrm{~min}$ at room temperature. Finally, the tissue sections were stained with 3'-diaminobenzidine and hematoxylin for $3 \mathrm{~min}$, both at room temperature. Stained tissue sections were observed under a light microscope (magnification, x400). Subsequently, NGF and TrkA expression in the lung was analyzed with Tissue Studio quantitative software (version 2.1; Definiens AG, Munich, Germany).

Western blot assay. Lung tissues were homogenized and total proteins were extracted in radioimmunoprecipitation assay lysis buffer (Beyotime Institute of Biotechnology) containing $1 \mathrm{mM}$ phenylmethylsulfonyl fluoride. Following determination of the protein concentration using a bicinchoninic acid protein assay kit (Pierce; Thermo Fisher Scientific, Inc.), equal amounts of total lung protein $(40 \mu \mathrm{g})$ were loaded onto $12 \%$ SDS/PAGE, and then transferred to a polyvinylidene membrane (EMD Millipore, Billerica, MA, USA). Non-specific binding sites on the PVDF membrane were blocked by 5\% skimmed milk PBST for $1 \mathrm{~h}$ at room temperature. Then, the PVDF membranes were incubated with NGF (1:1,000; cat. no. ab6199; Abcam) and TrkA (1:1,000; cat. no. ab76291; Abcam) primary antibodies for $2 \mathrm{~h}$ at $4^{\circ} \mathrm{C}$, and subsequently incubated with HRP-labeled goat anti-mouse IgG (1:1,000; cat. no. A0216; Beyotime Institute of Biotechnology) secondary antibody for $2 \mathrm{~h}$ at room temperature. The protein bands were visualized via a chemiluminiscence method. (PerkinElmer, Inc., Waltham, MA, USA). To normalize the loading amounts, $\beta$-actin served as an internal control. Protein bands were quantified by Quantity One software (version 4.62; Bio-Rad Laboratories, Inc.).

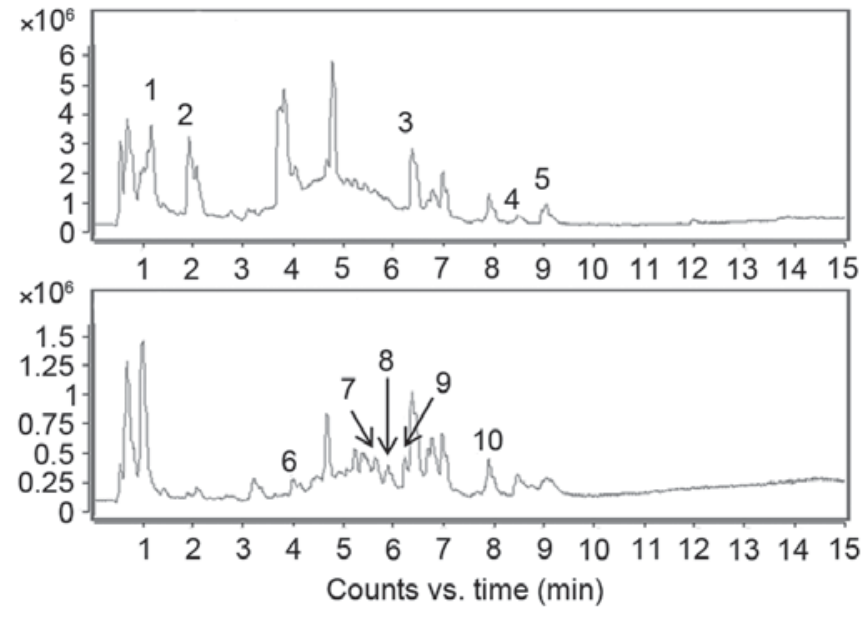

Figure 1. High-performance liquid chromatography-electrospray ionization tandem-mass spectrometry chromatogram of the aqueous extract in positive and negative mode.

Statistical analysis. All the data are presented as mean \pm standard deviation. Statistical analyses were performed using GraphPad Prism (version 5; GraphPad Software, Inc., La Jolla, CA, USA). Statistical comparisons were performed using one-way analysis of variance followed by Tukey's post hoc test. $\mathrm{P}<0.05$ was considered to indicate a statistically significant difference.

\section{Results}

HPLC assay for LSPF. The chemical compositions of LSPF aqueous extracts were determined by HPLC-ESI-MS in positive and negative-ion mode (Fig. 1). Compounds 1-10 with retention times $1.18,1.93,6.39,8.97,9.04,4.11,5.90,5.92,6.20$ and $7.90 \mathrm{~min}$ respectively were identified as D-leucine (1), DL-cysteine (2), baicalin (3), wogonin (4), tabersonine (5), tanshinone IIA (6), isoliquiritin (7), salvianolic acid B (8), rosmarinic acid (9) and glycyrrhizic acid (10), on the basis of the pseudo-molecular ion peak at $\mathrm{m} / \mathrm{z} 132.0971[\mathrm{M}+\mathrm{H}]^{+}(1)$, $\mathrm{m} / \mathrm{z} 144.0476[\mathrm{M}+\mathrm{Na}]^{+}(2), \mathrm{m} / \mathrm{z} 447.0933[\mathrm{M}+\mathrm{H}]^{+}(3)$, $\mathrm{m} / \mathrm{z} 285.0762[\mathrm{M}+\mathrm{H}]^{+}(4), \mathrm{m} / \mathrm{z} 375.1081[\mathrm{M}+\mathrm{K}]^{+}(5), \mathrm{m} / \mathrm{z}$ 293.1238 [M - H] $^{-}(6), \mathrm{m} / \mathrm{z} 417.0829$ [M - H] $^{-}$(7), m/z 753.2241 $\left[\mathrm{M}+\mathrm{Cl}^{-}(8), \mathrm{m} / \mathrm{z} 359.0772[\mathrm{M}-\mathrm{H}]^{-}(9), \mathrm{m} / \mathrm{z} 269.0464\right.$ [M - H] $]^{-}(10)$, in HPLC/ESI-MS chromatogram, in accordance with the ten compounds mentioned above. A total of 10 compounds were unambiguously identified by comparing the retention times, molecular weights and the MS data with the ten reference standards.

Inflammatory cells in BALFs decrease following LSPF treatment. As presented in Fig. 2A and B, following sensitization by OVA, the number of white cells $(\mathrm{P}<0.01)$ and eosinophils cells $(\mathrm{P}<0.01)$ in mice BALFs were significantly increased, compared with normal mice. The Dxm-treated mice had a significantly decreased number of white cells $(\mathrm{P}<0.01)$ and eosinophils cells $(\mathrm{P}<0.01)$, compared with the asthma model mice. Similar to the Dxm group, following treatment with LSPF at the doses of 300 and $600 \mathrm{mg} / \mathrm{kg}$, the number of white cells $(\mathrm{P}<0.01)$ and eosinophils cells $(\mathrm{P}<0.01)$ were significantly decreased, compared with asthma model mice. 
A

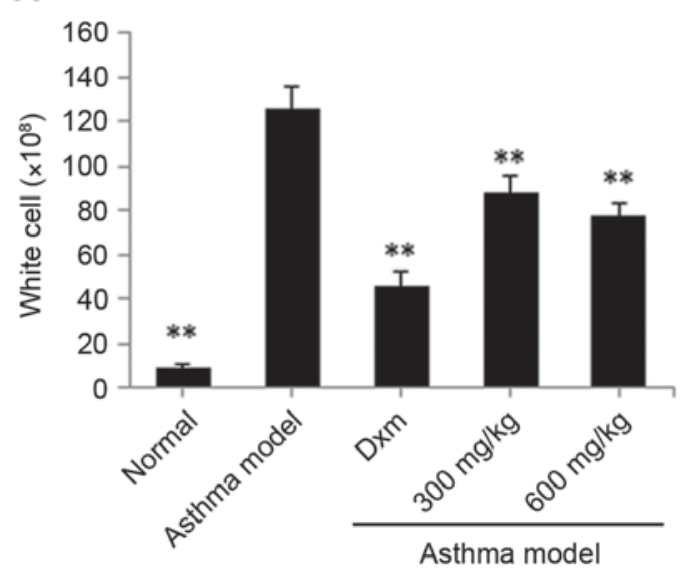

B

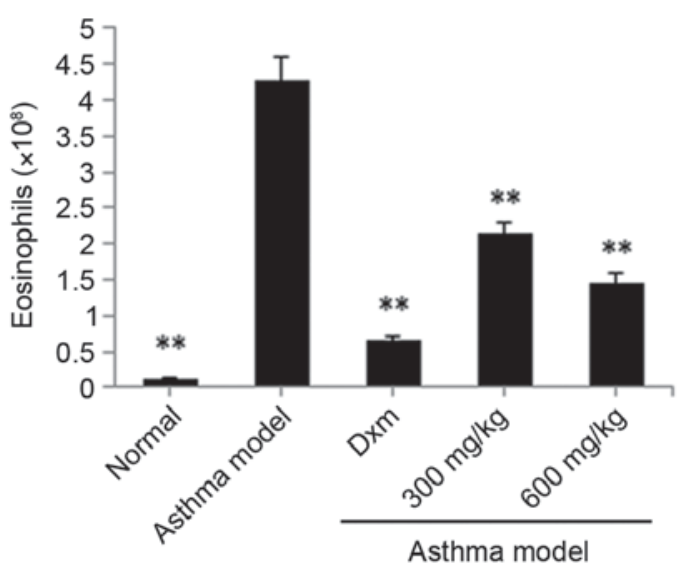

Figure 2. Effects of LSPF on inflammatory cells in BALFs. Following sensitization by $10 \%$ ovalbumin and inhalation of a $5 \%$ OVA solution, in the absence or presence of Dxm or LSPF, the number of (A) white cells and (B) eosinophils cells in mice BALFs were assessed by counting cells with a hemocytometer. Data are presented as the mean \pm standard deviation. ${ }^{* *} \mathrm{P}<0.01$ vs. asthma model mice. LSPF, liver soothing pingchuan formula; BALFs, bronchoalveolar lavage fluid; Dxm, Dexamethasone.
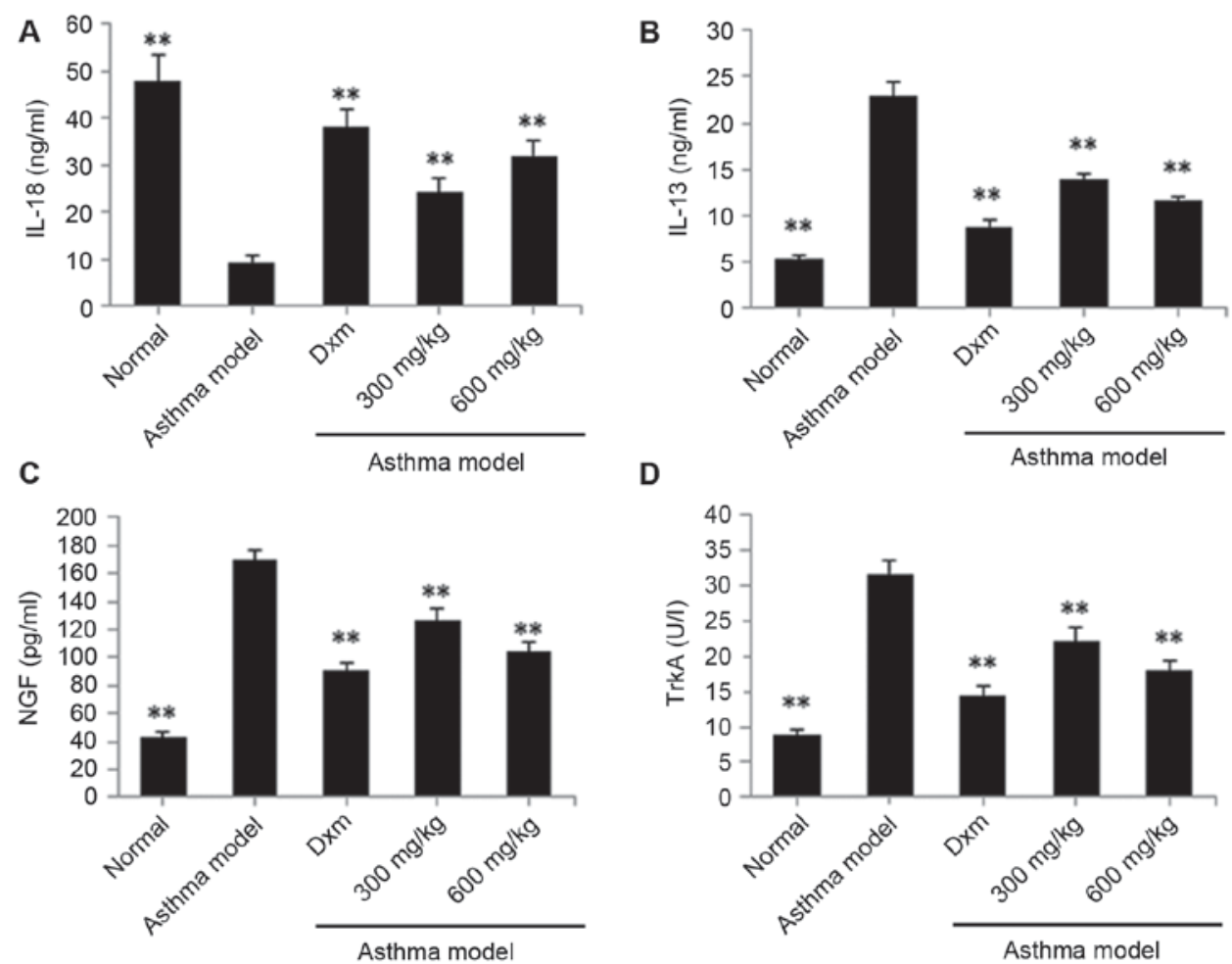

E

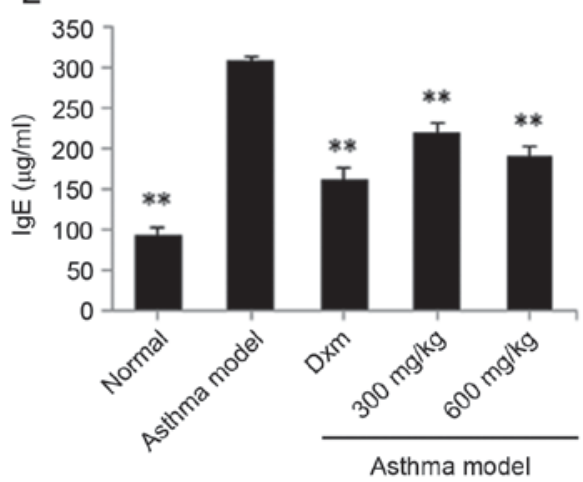

Figure 3. Effects of LSPF on IL-18, IL-13, NGF, TrkA and IgE levels in bronchoalveolar lavage fluid. Following sensitization by $10 \%$ ovalbumin and inhalation of a 5\% OVA solution in the absence or presence of Dxm or LSPF, (A) IL-18, (B) IL-13, (C) NGF, (D) TrkA and (E) IgE concentrations were measured by ELISA. Data are presented as the mean \pm standard deviation. ${ }^{* *} \mathrm{P}<0.01$, vs. asthma model mice. LSPF, liver soothing pingchuan formula; Dxm, Dexamethasone; IL, interleukin; NGF, nerve growth factor; TrkA, tyrosine kinase A; IgE, immunoglobulin E. 
Table II. Expression levels of NGF and TrkA in lung tissues of BALB/c mice.

\begin{tabular}{lrr}
\hline & NGF $\left(\mu \mathrm{m}^{2}\right)$ & $\operatorname{TrkA}\left(\mu \mathrm{m}^{2}\right)$ \\
\hline Normal & $40,581.50 \pm 11,533.719^{\mathrm{a}}$ & $8,573.83 \pm 2,992.04^{\mathrm{a}}$ \\
Asthma model & $70,647.50 \pm 26,511.302$ & $47,820.17 \pm 11,207.00$ \\
Asthma model +Dxm & $44,305.50 \pm 6,147.491^{\mathrm{a}}$ & $16,420.00 \pm 8,956.93^{\mathrm{a}}$ \\
Asthma model +300 mg/kg & $47,018.67 \pm 11,470.736^{\mathrm{a}}$ & $20,393.33 \pm 9,421.34^{\mathrm{a}}$ \\
Asthma model +600 mg/kg & $43,769.67 \pm 14,267.271^{\mathrm{a}}$ & $26,755.67 \pm 9,421.34^{\mathrm{a}}$
\end{tabular}

Data are presented as the mean \pm standard deviation. ${ }^{\mathrm{a}} \mathrm{P}<0.01$ vs. asthma model mice. Dxm, Dexamethasone; NGF, nerve growth factor; TrkA, tyrosine kinase A.
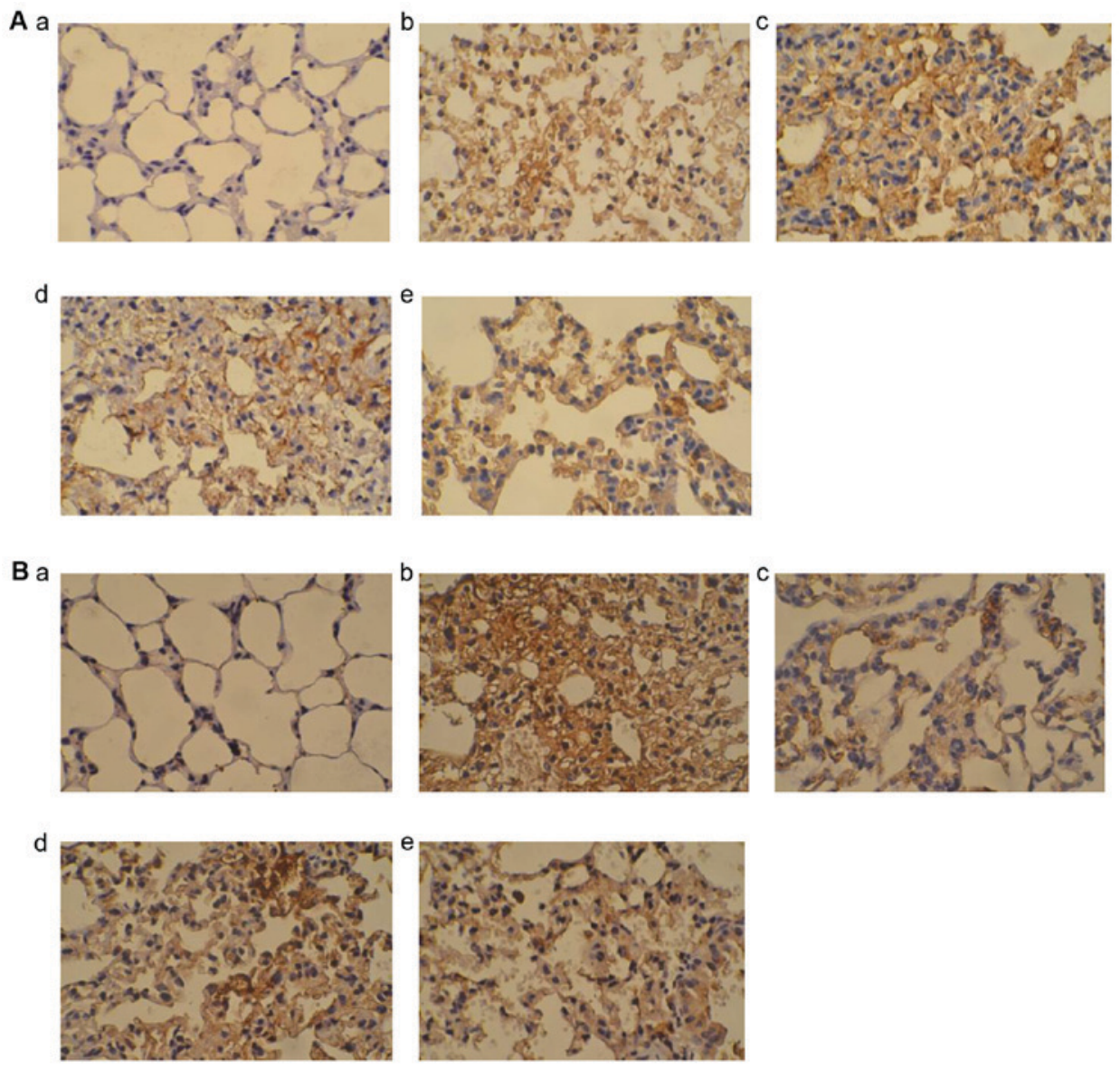

Figure 4. Expression levels of NGF and TrkA in lung tissues of BALB/c mice. Following sensitization by $10 \%$ ovalbumin and inhalation of a 5\% OVA solution in the absence or presence of Dxm or LSPF, the (A) NGF and (B) TrkA protein expression levels were measured by immunohistochemical assay. Magnification x400; brown color represents the protein expression of NGF and TrkA. (a), normal; (b), asthma model; (c), Dxm; (d), 300 mg/kg LSPF; (e), 600 mg/kg LSPF. LSPF, liver soothing pingchuan formula; Dxm, Dexamethasone; NGF, nerve growth factor; TrkA, tyrosine kinase A.

LSPF reverses asthma-induced alterations of cytokine and protein expression levels in BALFs. As presented in Fig. 3, the levels of IL-13 $(\mathrm{P}<0.01), \mathrm{NGF}(\mathrm{P}<0.01)$, TrkA $(\mathrm{P}<0.01)$ and $\operatorname{IgE}(\mathrm{P}<0.01)$ in BALFs of asthma model mice were significantly increased compared with normal mice, whereas the IL-18 levels were significantly decreased $(\mathrm{P}<0.01)$. Similar to the Dxm-treated mice, LSPF treatment (300 and $600 \mathrm{mg} / \mathrm{kg}$ ) significantly decreased the levels of IL-13 $(\mathrm{P}<0.01)$, NGF $(\mathrm{P}<0.01)$, TrkA $(\mathrm{P}<0.01)$ and $\operatorname{IgE}(\mathrm{P}<0.01)$, however increased the IL-18 levels $(\mathrm{P}<0.01)$ in BALFs, compared with the asthma model mice.
NGF and TrkA expression levels decrease with administration of LSPF. Results of the histopathological examination are presented in Fig. 4 and Table II. Compared with the normal mice, expression levels of NGF $(\mathrm{P}<0.01)$ and TrkA $(\mathrm{P}<0.01)$ were significantly upregulated in the lung tissues of asthma model mice, compared with the normal mice. Notably, the results indicated that treatment with LSPF reversed these alterations in asthmatic mice. As demonstrated in Fig. 4 and Table II, following treatment with LSPF (300 and $600 \mathrm{mg} / \mathrm{kg}$ ), the expression levels of NGF $(\mathrm{P}<0.01)$ and TrkA $(\mathrm{P}<0.01)$ were significantly downregulated, compared with the asthma model 

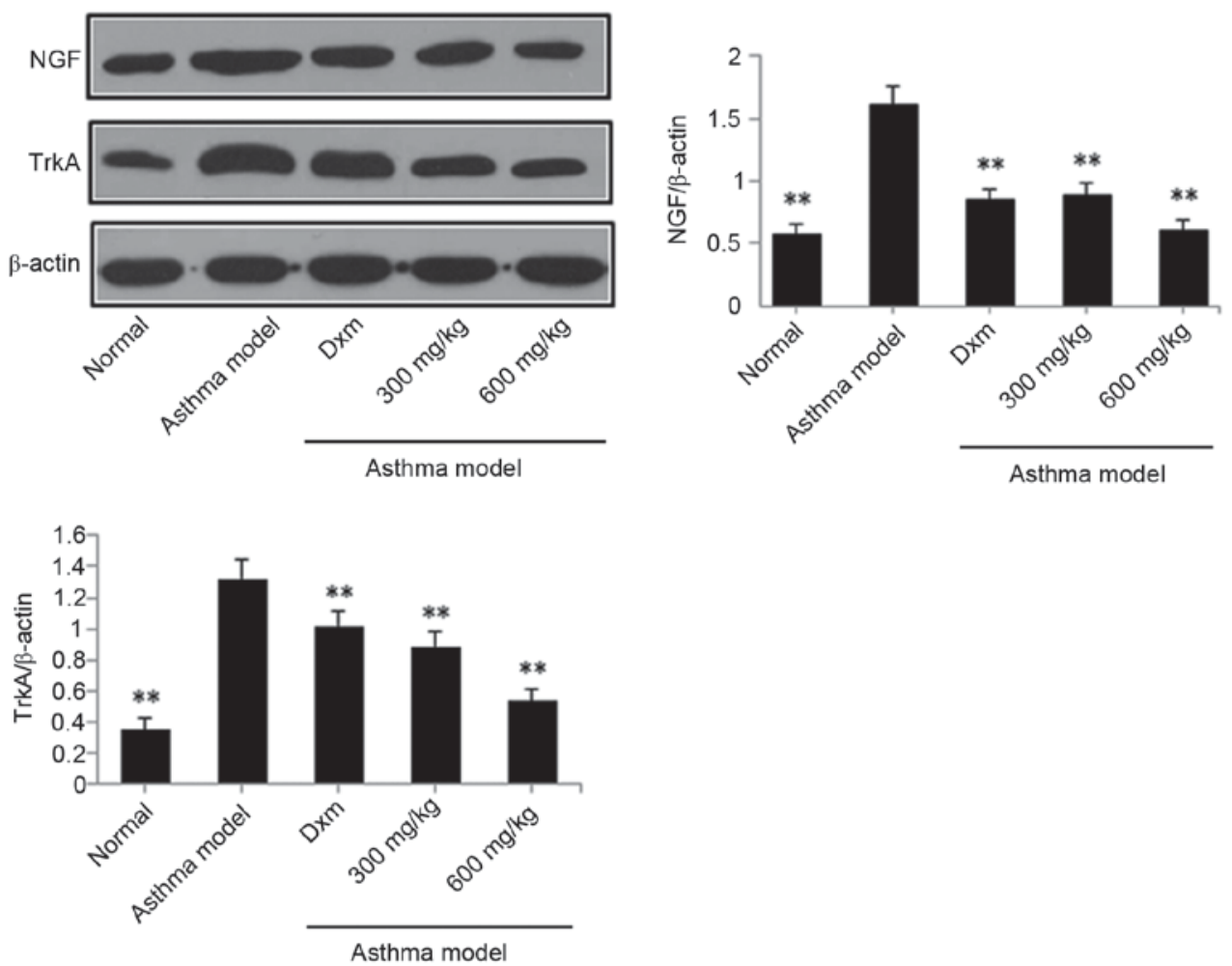

Figure 5. Effects of LSPF on expression levels of NGF and TrkA in lung tissues. Following sensitization by $10 \%$ ovalbumin and inhalation of a 5\% OVA solution in the absence or presence of Dxm or LSPF, the NGF and TrkA protein expression was measured by western blot assay. Data are presented as the mean \pm standard deviation. ${ }^{* *} \mathrm{P}<0.01$ vs. asthma model mice. LSPF, liver soothing pingchuan formula; Dxm, Dexamethasone; NGF, nerve growth factor; TrkA, tyrosine kinase A.

mice. In addition, the Dxm-treatment resulted in a similar effect to the LSPF.

LSPF reverses asthma-induced alterations in NFG and Trk- $A$ levels, detected by western blotting. As presented in Fig. 5, the protein expression levels of NFG and TrkA were upregulated $(\mathrm{P}<0.01)$ by challenging with OVA (asthma model mice), compared with normal mice. In accordance with the results obtained from the Dxm-treated mice, the protein expression levels of NFG $(\mathrm{P}<0.01)$ and TrkA $(\mathrm{P}<0.01)$ were downregulated by treatment with LSPF (300 and $600 \mathrm{mg} / \mathrm{kg}$ ), compared with asthma model mice.

\section{Discussion}

The present study examined the potential therapeutic effect of LSPF on asthma using an OVA-induced asthmatic mouse model. The results indicated that LSPF suppressed the inflammatory cells including white cells and eosinophil cells that typically appear in the airway during asthma attacks. In addition, LSPF significantly suppressed the levels of $\mathrm{IgE}, \mathrm{IL}-13$ and increased the level of IL-18 in the BALFs, and the results indicated that the potential pharmacological mechanisms may be associated with downregulation of the NGF-TrkA pathway.

It has previously been demonstrated that asthma is closely associated with allergen-specific type $2 \mathrm{~T}$ helper (Th2) lymphocyte proliferation, which may result in excessive production of Th2 cytokines, including IL-13, resulting in over-release of allergen-specific $\operatorname{IgE}(2,23,24)$. IL-13 exhibits a crucial role in the effector phase of Th2 responses, including eosinophilic infiltration and mucus hypersecretion $(18,25,26)$. Inhibition of the airway inflammatory reaction may be beneficial for relieving and controlling the symptoms of asthma, and the abnormal increase of white cells and eosinophil cells is an indication of an inflammatory reaction $(15,27,28)$. In addition, increasing evidence demonstrates that inhibition of $\mathrm{IgE}$ is an effective strategy for treating asthma $(18,29)$. IL-18, an inducing factor of interferon- $\gamma$, effectively relieves the airway hyperreactivity and downregulates the $\mathrm{IgE}$ and eosinophil levels $(30,31)$. The results demonstrated that LSPF suppressed the white cells and eosinophil cells in BALFs; in addition, the present study additionally demonstrated that LSPF effectively downregulated IgE and IL-13 and upregulated IL-8. The findings suggested that LSPF may be helpful for treating or relieving the airway symptoms of asthma.

NGF is a neurotrophic factor that maintains the survival of central and peripheral neurons and facilitates their growth, differentiation and regeneration. NGF has recently elicited a strong interest regarding its roles in immune, reproductive, cell proliferation and hematopoietic processes (32-35). A Th1/Th2 immune imbalance induces neurogenic inflammation by increasing the expression of NGF mRNA; it has additionally been demonstrated that NGF induces atopic dermatitis by promoting a shift from a Th1 to a Th2-type immune response by enhancing the expression of GATA binding protein-3 $(36,37)$. The present study selected NGF and TrkA as observation indices to evaluate the therapeutic effects of LSPF on Th1/Th2 immune imbalance-associated neurogenic inflammation. The results indicated that LSPF significantly 
downregulated the expression levels of NGF and TrkA in lung tissues of OVA challenged mice, which may act as a foundation for future studies regarding the therapeutic effects of LSPF on neurogenic inflammation in asthma.

In conclusion, the results suggested that LSPF exhibits potential therapeutic effects on experimental asthma in $\mathrm{BALB} / \mathrm{c}$ mice, and the pharmacological mechanisms may be associated with the downregulation of the NGF-TrkA signaling pathway.

\section{Acknowledgements}

Not applicable.

\section{Funding}

The present study was supported by the National Natural Science Foundation Project (grant no. 81202723); the Shanghai Traditional Chinese Medicine Schools Heritage Research Base Project(XuPediatrics; grantno.ZYSNXD-CC-HPGC-JD-005); the Shanghai Xinglin Nova Plan (grant no. ZYSNXD011-R C-XLXX-20130040); the National Postdoctoral Project of an Inheriting Chinese Medicine Master (2013; grant no. 240) and the Shanghai Leading Talent Project of Chinese Medicine (2012; grant no. 053).

\section{Availability of data and materials}

The analyzed datasets generated during the study are available from the corresponding author on reasonable request.

\section{Author's contributions}

XGZ, ZX and JEY conceived and designed the experiments. YTZ, LB and FL performed the experiments and analyzed the data. LQL, JW and JDZ performed the experiments and contributed the reagents, materials and analysis tools. XGZ and JEY wrote the paper. All authors read and approved the final manuscript.

\section{Ethics approval and consent to participate}

The present study was approved by the Ethics Committee of Shanghai Municipal Hospital of Traditional Chinese Medicine (Shanghai, China).

\section{Consent for publication}

Not applicable.

\section{Competing interests}

The authors declare that they have no competing interests.

\section{References}

1. Pearce N, Ait-Khaled N, Beasley R, Mallol J, Keil U, Mitchell E and Robertson C; ISAAC Phase Three Study Group: Worldwide trends in the prevalence of asthma symptoms: Phase III of the international study of asthma and allergies in childhood (ISAAC). Thorax 62: 758-766, 2007.
2. Xu X, Wang HY, Zhang ZW, Han $\mathrm{H}$ and Wang Y: Effect of massage therapy on pulmonary functions of pediatric asthma: A systematic review and meta-analysis of randomized controlled trials. Eur J Integr Med 8: 98-105, 2016.

3. Szefler SJ: Advances in pediatric asthma in 2013: Coordinating asthma care. J Allergy Clin Immunol 133: 654-661, 2014.

4. Feldman AS, He Y, Moore ML, Hershenson MB and Hartert TV: Toward primary prevention of asthma: Reviewing the evidence for early-life respiratory viral infections as modifiable risk factors to prevent childhood asthma. Am J Respir Crit Care Med 191: 34-44, 2015.

5. Haselkorn T, Fish JE, Zeiger RS, Szefler SJ, Miller DP, Chipps BE, Simons FE, Weiss ST, Wenzel SE, Borish L, et al: Consistently very poorly controlled asthma, as defined by the impairment domain of the expert panel report 3 guidelines, increases risk for future severe asthma exacerbations in the Epidemiology and natural history of asthma: Outcomes and treatment regimens (TENOR) study. J Allergy Clin Immunol 124: 895-902.e1-e4, 2009.

6. Freund V and Frossard N: Expression of nerve growth factor in the airways and its possible role in asthma. Prog Brain Res 146: 335-346, 2004.

7. Renz H: Neurotrophins in bronchial asthma. Respir Res 2: 265-268, 2001.

8. Nassenstein C, Dawbarn D, Pollock K, Allen SJ, Erpenbeck VJ, Spies E, Krug N and Braun A: Pulmonary distribution, regulation and functional role of Trk receptors in a murine model of asthma. J Allergy Clin Immunol 118: 597-605, 2006.

9. Graham RM, Friedman M and Hoyle GW: Sensory nerves promote ozoneinduced lung inflammation in mice. Am J Respir Crit Care Med 164: 307-313, 2001.

10. Freund-Michel V, Bertrand C and Frossard N: TrkA signalling pathways in human airways mooth muscle cell proliferation. Cell Signal 18: 621-627, 2006.

11. Nakamura T, Komiya M, Sone K, Hirose E, Gotoh N, Morii H, Ohta Y and Mori N: Grit, a GTPase-activating protein for the Rho family, regulates neurite extension through association with the TrkA receptor and $\mathrm{N}-\mathrm{Shc}$ and $\mathrm{CrkL} / \mathrm{Crk}$ adapter molecules. Mol Cell Biol 22: 8721-8734, 2002.

12. Huang LW, Sun G, Wang DL and Kong LF: Inhibition of nerve growth factor/tyrosine kinase receptor a signaling ameliorates airway remodeling in chronic allergic airway inflammation. Eur Rev Med Pharmacol Sci 19: 2261-2268, 2015.

13. Ni X,Li X,Fang X,Li N, Cui W and Zhang B: NGF/TrkA-mediated Kidins220/ARMS signaling activated in the allergic airway challenge in mice. Ann Allergy Asthma Immunol 105: 299-306, 2010.

14. Li L, Kong L, Fang X, Jiang C, Wang Y, Zhong Z, Sun Q, Gu G, Zheng D, Meng R and Kang J: SH2-B beta expression in alveolar macrophages in BAL fluid of asthmatic guinea pigs and its role in NGF-TrkA-mediated asthma. Respirology 14: 60-68, 2009.

15. Shin IS, Lee MY, Jeon WY, Shin NR, Seo CS and Ha H: EBM84 attenuates airway inflammation and mucus hypersecretion in an ovalbumin-induced murine model of asthma. Int J Mol Med 31: 982-988, 2013.

16. Lee MY, Shin IS, Jeon WY, Lim HS, Kim JH and Hyekyung H: Pinellia ternata Breitenbach attenuates ovalbumin-induced allergic airway inflammation and mucus secretion in a murine model of asthma. Immunopharmacol Immunotoxicol 35: 410-418, 2013.

17. Yu J, Li L, Zhang X, Xia Y, Huo L and Zhang X: Study of pingchuan formula's effects on Th1/Th2 of bronchial asthma in model rats. J Pediatr Trad Chin Med 1: 009, 2006 (In Chinese).

18. Li L, Yu J, Zhang X, Min W and Xia Y: Pingchuan Formula for children's bronchial asthma: An observation of 30 cases. J Pediatr Trad Chin Med 1: 007, 2008 (In Chinese).

19. Li YK: Chinese Medicine Pharmacology Experiment Methodology. 2nd edition. Shanghai Science and Technology Press, Shanghai, pp119-120, 2006.

20. Zhang X, Yu J, Xue Z, Li L, Bai L, Liu F and Wu J: Intervention on IL-13/IL-18 imbalance in asthma mice treated with the therapy for resolving phlegm, removing stasis and soothing the liver. World J Integr Trad West Med 8: 344-347, 377, 2013 (In Chinese).

21. Zhang XG, Liu F, Xue Z, Li LQ, Liu F, Bai L and Yu JE: Effect of preictal phase intervention of phlegm-stasis resolving and liver soothing method on NGF-TrkA signaling pathway of murine model of asthma. World Chin Med 8: 652-655, 2013. 
22. Peng W, Qiu XQ, Shu ZH, Liu QC, Hu MB, Han T, Rahman K, Qin LP and Zheng CJ: Hepatoprotective activity of total iridoid glycosides isolated from Paederia scandens (lour.) Merr. var. tomentosa. J Ethnopharmacol 174: 317-321, 2015.

23. Holt PG and Sly PD: Viral infections and atopy in asthma pathogenesis: New rationales for asthma prevention and treatment. Nat Med 18: 726-735, 2012.

24. Matsuse H, Fukushima C, Fukahori S, Tsuchida T, Kawano T, Nishino T and Kohno S: Differential effects of dexamethasone and itraconazole on Aspergillus fumigatus exacerbated allergic airway inflammation in a murine model of mite-sensitized asthma. Respiration 85: 429-435, 2013.

25. Lukacs NW: Role of chemokines in the pathogenesis of asthma. Nate Rev Immunol 1: 108-116, 2001.

26. Galli SJ, Tsai M and Piliponsky AM: The development of allergic inflammation. Nature 454: 445-454, 2008.

27. Abdureyim S, Amat N, Umar A, Upur H, Berke B and Moore N: Anti-inflammatory, immunomodulatory and heme oxygenase-1inhibitory activities of Ravan Napas, a formulation of Uighur traditional medicine, in a rat model of allergic asthma. Evid Based Complement Alternat Med 2011: 725926, 2011.

28. Busse WW and Rosenwasser LJ: Mechanisms of asthma. J Allerg Clin Immunol 111 (3 Suppl): S799-S804, 2003.

29. Pelaia G, Vatrella A, Busceti MT, Fabiano F, Terracciano R, Matera MG and Maselli R: Molecular and cellular mechanisms underlying the therapeutic effects of budesonide in asthma. Pulm Pharmacol Ther 40: 15-21, 2016.

30. Raupach B, Peuschel SK, Monack DM and Zychlinsky A: Caspase-1-mediated activation of interleukin-1 beta; (IL-beta) and IL-18 contribute to innate immune defenses against Salmonella enteric serovar typhimurium infection. Infect Immun 74: 4922-4926, 2006.
31. Okamura H, Tsutsih H, Komatsu T, Yutsudo M, Hakura A, Tanimoto T, Torigoe K, Okura T, Nukada Y, Hattori K, et al: Cloning of a new cytokine that induces IFN-gamma production by T cells. Nature 378: 88-91, 1995.

32. Wilfong ER and Dey RD: The release of nerve growth factor from the nasal mucosa following toluene diisocyanate. J Toxicol Environ Health A 68: 1337-1348, 2005.

33. Li C, Watanabe G, Weng Q, Jin W, Furuta C, Suzuki AK, Kawaguchi $\mathrm{M}$ and Taya $\mathrm{K}$ : Expression of nerve growth factor (NGF), and its receptors TrkA and p75 in the reproductive organs of the adult male rats. Zoolog Sci 22: 933-937, 2005.

34. Park MJ, Kwak HJ, Lee HC, Yoo DH, Park IC, Kim MS, Lee SH, Rhee $\mathrm{CH}$ and Hong SI: Nerve growth factor induces endothelial cell invasion and cord formation by promoting matrix metalloproteinase-2 expression through the phosphatidylinositol 3-kinase/Akt signaling pathway and AP-2 transcription factor. J Biol Chem 282: 30485-30496, 2007.

35. Triaca $\mathrm{V}$ and Aloe L: Neuronal markers expression of NGF-primed bone marrow cells (BMCs) transplanted in the brain of 6-hydroxydopamine and i-botenic acid lesioned littermate mice. Neurosci Lett 384: 82-86, 2005

36. He RG, Wu SG, Wu YX, Wu QX and Tian H: The effect of nerve growth factor on Th1/Th2 cell immune imbalance in atopic dermatitis mice model. Chin J Dermatovenereol 24: 109-111, 2010 (In Chinese).

37. Jin YL, Li Q and Han J: Study on the effect of nerve growth factor on Th1/Th2 cell immune imbalance in asthmatic mice. Chin Labor Dia 12: 595-597, 2008 (In Chinese). 